\title{
RELATIONSHIP OF SUTURE MATERIAL TO HEALING IN THORACOPLASTY WOUNDS*
}

R. W. Buxton, M.D.

Instructor in Surgery, University of Michigan Hospital

ANN ARBOR, MICHIGAN

$\mathrm{L}^{\mathrm{AN}}$ NGSTON $^{1}$ has recently stressed the importance of the rôle of sensitivity to catgut in the healing of thoracoplasty wounds. His study of these wounds in this clinic revealed a striking difference in the healing of wounds closed with catgut and those closed with silk. However, his major premise was the allergic manifestations of catgut. Since his data were compiled, nonabsorbable suture material has been used in enough thoracoplasty operations to allow a large scale comparison of the two methods of closure. The purpose. of this paper is to present a statistical study of the wound healing of 809 consecutive thoracoplasty stages performed on I95 patients from January, I940, to January, I942. The incisions were closed with catgut in 538 cases and with silk in $27 \mathrm{I}$ cases. Wound healing was studied not only in relation to the suture material used but also in relation to the method of suturing. ${ }^{4}$

One-half of the catgut wounds were closed with a continuous suture (which was occasionally interrupted), approximating the muscles in one layer with No. o or No. oo chromic catgut. In most of the cases the subcutaneous fascia was approximated with interrupted No. ooo chromic catgut and the skin with interrupted silk. In the silk cases, each of the muscle layers was closed with interrupted No. I silk passed in small bites chiefly through the fascia; the subcutaneous fascia and skin were closed separately with interrupted No. I silk.

In the following study, all postoperative wound complications were distributed into three arbitrary groups:

* From the Department of Surgery, Section of Thoracic Surgery, University of Michigan, Ann Arbor, Michigan.
M. L. White, JR., M.D.

Assistant Professor of Surgery, University of Virginia Hospital

CHARLOTTESVILLE, VIRGINIA

Group A. Demonstrable fluid beneath the skin or muscles but without infection; slight skin separation with or without spontaneous escape of accumulated wound fluid, but without infection; indurated or red, "beefy" wounds which did not suppurate; small areas of skin necrosis in the suture line.

Group B. All subcutaneous wound infections with pyogenic organisms.

Group c. Submuscular or subscapular pyogenic wound infections; all tuberculous wound infections.

Of the 809 wounds studied, I 2 I showed complications of the above varieties, an incidence of I 4.9 per cent. Not included are three wound complications obviously not related to the present study. Two of these were wound suppurations from empyema necessitatis, and one was a massive hemorrhage into the subscapular space following nine days of heparinization for a femoral embolus. Of the 538 thoracoplasty wounds closed with catgut, I02 developed wound difficulties, an incidence of 18.9 per cent. Nineteen or 7.0 per cent of the 27 I wounds closed with silk had some complication.

Further analysis of the catgut wounds showed that different methods of closure had little influence upon the incidence of wound complications. Among 270 incisions closed with the continuous technic, fiftythree had complications, an incidence of I9. 6 per cent. Of the 217 wounds in which an interrupted catgut closure was used, forty-four or 20.2 per cent had healing abnormalities. In fifty-one cases closed with catgut the surgeon failed to state 
the manner of closure. This group had five, or 9.8 per cent, cases of poor healing.

Table I gives a detailed analysis of the type of complications occurring with the two types of suture material and with the method of closure.

TABLE I

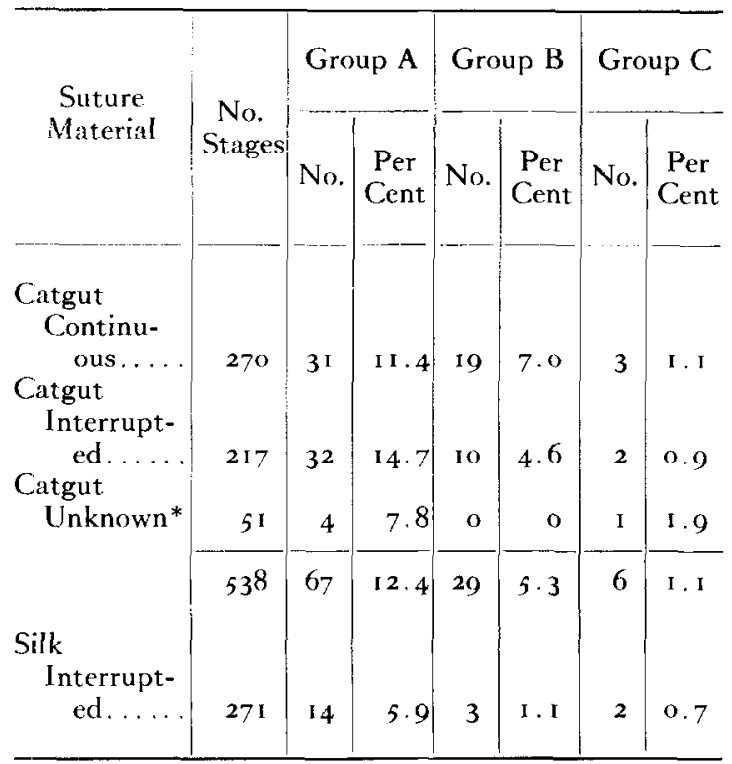

* Method of closure not stated by surgeon.

In the above table, Group A is worthy of special note. The great majority of cases placed in this group were those showing a red, edematous, "beefy" wound, usually with the formation of excessive wound fluid. The percentage of catgut wounds with this complication more than doubled the percentage of similar silk wounds. This is in accordance with the frndings in this and other clinics which suggest that these complications may be due to catgut sensitivity. In none of these wounds did the inflammatory process proceed to frank suppuration.

Group a complications were never serious, and rarely delayed the subsequent operative stages. Groups B and c, therefore, comprise the complications which presented a threat to life or decreased the effectiveness of the thoracoplasty collapse by delaying further rib resection. Considering, therefore, the serious complications, it was found that 6.5 per cent of the catgut wounds fell into this classification, as contrasted with only I. 8 per cent of the silk technic wounds. Serious complications occurred three and one-half times more frequently in wounds closed with absorbable sutures. In none of the I95 patients who are the object of this study did the wound infection happen to be fatal.

Effect of Apicolysis. It has been stated that in the process of extrafascial separation of the pulmonary apex, numerous Iymph channels are-severed. By postulation, a higher incidence of deep wound infection should follow this procedure than follows a simple thoracoplasty. An apicolysis was done or attempted in forty-six of the 166 patients receiving a primary first-stage thoracoplasty. In none of the patients upon whom secondary or revision thoracoplasties were done was an apicolysis attempted. Eight of these forty-six patients developed postoperative wound complications, an incidence of 17.4 per cent. This percentage complication, however, appears of little significance since nineteen patients developed wound difficulties among the I 5 I patients receiving either primary or secondary first-stage thoracoplasties without apicolysis. This is an incidence of I2.5 per cent.

TABLE II

PRIMARY FIRST-STAGE THORACOPLASTIES WITH APICOLYSIS

\begin{tabular}{c|c|c|c|c}
\hline $\begin{array}{c}\text { Total } \\
\text { Patients }\end{array}$ & Closure & Group A & Group B & Group c \\
\hline \multirow{3}{*}{46} & Catgut & 3 & 4 & 0 \\
& Silk & $\mathbf{I}$ & 0 & 0 \\
\hline
\end{tabular}

In Table II it is notable that no deep submuscular or subscapular wound infections (Group c) appeared in this series of forty-six patients. In none of the fortysix patients, however, was an extensive apicolysis done. The extent of the extrafascial separation was never more than necessary to drop the apex to the level of the third rib posteriorly. 
Effect of Formalin. The rubbing of the periosteum with io per cent formalin solution is the present method used in this hospital to prevent rapid stiffening of the thoracic wall by the formation of regenerated ribs between operative stages. Formalin was used on the exposed periosteal beds in 458 stages, or 56.6 per cent of the total number of operative stages. Seventy of these patients developed wound complications, an incidence of I $\mathbf{5 . 2}$ per cent. The stages in which no formalin was used numbered $35 \mathrm{I}$; of these, fifty-four developed postoperative wound difficulties, an incidence of 15.3 per cent. The use of formalin cannot, therefore, be indicted in the production of wound complications.

Discussion. In reviewing the statistics of this series of 809 consecutive thoracoplasty stages, it must be remembered that the thoracoplasty wound has certain peculiar characteristics which have been pointed out by Langston. The great length of the parascapular incision, the anatomical necessity of leaving an extrapleural subscapular space which collects serum, and the reopening of the wound several times at approximately twenty-one-day intervals, all should tend to increase the incidence of healing complications. Apart from these mechanical factors, patients requiring thoracoplasty all have a certain general debilitation from their chronic tuberculosis. No attempt has been made to correlate the age, extent of disease and nutritional or vitamin balance of the patient with the postoperative wound complications that occurred. In spite of these mechanical and other factors, it is interesting to note that the percentage of infected wounds in this series, namely, 6.4 per cent with catgut closure and 1.8 per cent with silk closure, compares favorably with the percentages of infected wounds reported in other studies. Whipple ${ }^{2}$ has compiled a seven-year study with $\mathbf{5 . 7}$ per cent infection with the use of catgut and 2.3 per cent with the use of silk in general surgical wounds. Brown ${ }^{3}$ quotes Goff's frgures of I0.0 per cent infection with catgut and 2.2 per cent with silk; Guthrie's figures of 2.9 per cent for catgut and I.27 per cent for silk; and Longacre's figures of I $_{5} .4$ per cent for catgut and 2.55 per cent for silk.

It may be added that since this study was carried out cotton has been used in our clinic with great satisfaction but there have as yet been too few wound closures with this suture material for statistical comparison of the complications. ${ }^{5}$

\section{SUMMARY}

The wounds of 809 consecutive thoracoplasty stages on 195 patients with pulmonary or pleural tuberculosis have been studied with relation to healing and the type of suture material used.

Minor or major complications occurred in 13.7 per cent of the wounds. The incidence was 18.9 per cent in the catgut wounds and 7.0 per cent in the silk wounds. By excluding all wound complications of a minor character and not specifically due to wound infection, the incidence was 6.5 per cent in the catgut series and I.8 per cent in the silk series.

\section{REFERENCES}

I. Langston, H. T. The problem of catgut sensitivity and its relation to wound healing. Ann. Surg., i I 5 : I 4 I - I 47, I 942.

2. Whipple, A. O. The essential principles in clean wound healing. Surg., Gynec. ob Obst., 70: 257-260, I940.

3. Brown, M. J. Silk and the surgical wound. J. Iowa State Med. Soc., 29: 600-602, 1939.

4. Shambaugh, P. Postoperative wound complications. Surg., Gynec. eo Obst., 64: 765-771, 1937.

5. Meade, W. H. and Long, C. H. The use of cotton as a suture material. J. A. M. A., 117:2140-2143, I94. I. 